\title{
PRELIMINARY STUDY REGARDING THE FORMULATION AND PHYSICAL EVALUATION OF SOME BIOCOMPATIBLE, OIL IN WATER MICROEMULSIONS WITH SALICYLIC ACID FOR DERMATOLOGIC USE
}

\author{
MARIA CRISTINA ANICESCU, CRISTINA ELENA DINU-PÎRVU, MIHAELA VIOLETA GHICA*, \\ MARINA THEODORA TALIANU, LĂCRĂMIOARA POPA
}

\author{
Department of Physical and Colloidal Chemistry, Faculty of Pharmacy, "Carol Davila" University of Medicine and \\ Pharmacy, 6 Traian Vuia Street, Bucharest, Romania
}

*corresponding author: mihaela.ghica@umfcd.ro

Manuscript received: January 2021

\begin{abstract}
Microemulsions (MEs) are considered a piece of new generation colloidal systems with high potential for drug delivery, especially for topical application. The present study had as main objectives the development and physical analysis of two groups of oil in water $(\mathrm{O} / \mathrm{W})$ microemulsion $(\mathrm{ME})$ vehicles using a biocompatible mixture composed of lecithin/Tween 80 as surfactants and propylene glycol (PG) as cosurfactant. The addition of vegetable oils and hyaluronic acid (HA) enriched the quality profile of the systems. The vehicles were suitable to entrap salicylic acid (SA) $0.5 \%$ as a model drug with keratoplastic properties, and positive outcomes in acne treatment. The study was divided in two stages of screening, resulting two groups of MEs. In the first case, lecithin was tested as potential surfactant on a domain of $0.5-2 \%$. A minimum amount of lecithin $0.5 \%$, in association with Tween 80 and PG was considered appropriate to obtain the second group of O/W MEs. In this case, were screened combinations of lecithin/Tween 80/PG able to solubilize SA $0.5 \%$ and small quantities of vegetable oils. All the microdispersions obtained in both stages were analysed considering visual appearance, conductivity, $\mathrm{pH}$ and refractive index as important parameters for systems' stability. The area of MEs generation for the second group, was specifically identified using graphical method. An extensive rheological analysis was considered to determine the flow behaviour for the most representative systems. It was concluded that minimal concentration of tensioactives that can promote stable and clear systems with SA was $30.5 \%$. This proportion was specific for a ME system formulated with $20 \%$ Tween 80 , $10 \%$ PG and $0.5 \%$ lecithin. Physical analysis performance emphasized preliminary data concerning the internal structure of microemulsions, offering a useful background for future studies.
\end{abstract}

\section{Rezumat}

Microemulsiile (MEs) reprezintă formulări ce aparţin noii generaţii de sisteme coloidale, cu înalt potenţial pentru cedarea medicamentului, în special pentru administrarea topică. Prezentul studiu a avut ca obiective principale dezvoltarea şi analiza fizică a două grupe de vehicule de tip microemulsie (ME) ulei în apă (U/A), utilizând un amestec biocompatibil format din lecitină/Tween 80 ca surfactanţi, alături de propilenglicol (PG) cu funcţie de cosurfactant. Au fost adăugate uleiuri vegetale şi acid hialuronic (HA), cu scopul de a îmbunătăţi profilul calitativ al sistemelor. Vehiculele formulate au fost adecvate pentru încorporarea acidului salicilic (SA) $0,5 \%$ ca medicament model cu proprietăţi keratoplastice și efecte pozitive în tratamentul acneei. Studiul a fost împărțit în două etape de screening, rezultând două grupe de microemulsii. În prima etapă, lecitina a fost testată ca potențial surfactant pe un domeniu de $0,5-2 \%$. Utilizarea lecitinei $0,5 \%$, alături de Tween 80 și PG, a fost considerată potrivită pentru obținerea celui de-al doilea set de sisteme U/A. În acest caz, au fost testate combinații conținând lecitină/Tween 80/PG, capabile să solubilizeze SA 0,5\% și cantități mici de ulei. Dispersiile obținute în cele două etape au fost analizate considerând aspectul, $\mathrm{pH}$-ul, conductivitatea şi indicele de refracţie ca parametri importanţi pentru stabilitatea sistemelor. Zona de generare a MEs, pentru cel de-al doilea grup, a fost identificată specific, utilizând metoda grafică. Pentru cele mai reprezentative sisteme, analiza reologică a fost abordată pentru a determina tipul de curgere. În concluzie, concentrația minimă de tensioactivi care poate asigura formarea unor sisteme clare și stabile cu SA a fost $30,5 \%$. Această proporţie a fost specifică unui sistem de tip ME formulat cu 20\% Tween 80, 10\% PG și 0,5\% lecitină. În urma analizei fizice, au fost evidențiate date preliminare asupra structurii interne a MEs, fiind apreciate ca o bază utilă pentru studii ulterioare.

Keywords: microemulsions, formulation factors, physical analysis, rheological evaluation

\section{Introduction}

Recent trends in pharmaceutical development are focused on fluid nanostructures and their amazing ability to entrap challenging active molecules with the aim to obtain an easy delivery access on both topical and systemic routes [8]. Balancing the advantages in the core of the expectations in order to prove a superior quality profile, colloidal microsystems are differentiating by far from conventional coarse dispersions [29]. 
Thus, microemulsions (MEs) are considered a new generation of colloidal systems with multiple applications in the pharmaceutical field being projected as modern platforms for drug delivery [25].

The concept of microemulsion dates from 1943, signifying a relatively long history and the presence of a solid knowledge concerning their soft physical principles that define it [19]. On the other hand, current research contributions were proposed in the last ten years, offering a generous background about the micro- and nano-structured domain, with emphasis on microemulsion and nanoemulsion design and their application in drug formulation and preparation [44]. Microemulsions are fluid, isotropic and thermodynamically stable systems composed of oil and water as two immiscible phases, dispersed in a tensioactive mixture formed with a surfactant (S) and a cosurfactant $(\mathrm{CoS})[12]$. Their clarity and elegant appearance are justified by a high grade of particle dispersion in the process of preparation which can be explained considering the presence of the fourth key element of formulation, absent in the coarse dispersion type, namely the $\mathrm{CoS}$, a medium-chain alcohol [18]. The phenomenon of dispersion, according with the thermodynamic theory suppose a decrease of the interfacial tension in the presence of surfactants and cosurfactants. As a result, particles will be stabilized by a doublecomposed monomolecular layer characterized by three factors: elasticity, a proper toughness and regeneration capacity against distortions. These were found to coexist in a balanced manner over a long time in experimental stability studies, describing flexible domains of microemulsion [30, 36, 41, 50].

The main objectives followed in the study of microemulsions are: the study of solubilization capacity of MEs in order to integrate lipophilic and hydrophilic molecules using a large spectrum of tensioactives; the study of formulation factors on MEs generation, their internal structure and their stability analysis, with repercussions on the final quality profile of the systems; obtaining a superior release of the active pharmaceutical ingredient (API) over in vitrolex vivo/in vivo tests; increasing drug potency due to its incorporation in MEs which seems to be superior than that of the unprepared API; minimizing the adverse reactions that commonly appear in conventional treatments; exploring their adaptability in order to create multifunctional systems [19, 48, 51, 53].

The previously mentioned approaches were reflected in several studies, with emphasis on topical administration of microemulsions as ideal vehicles for drug delivery. In this direction, Vlaia et al. proposed the integration of loratadine in microemulsions with anti-allergic properties at skin site [62]. Microemulsions based hydrogels for topical delivery of metoprolol tartrate were studied to increase its bioavailability [61]. In a recent study, preliminary formulation data were assessed considering fluconazole solubilization in microemulsion vehicles, using biocompatible surfactants like sucrose esters combined with essential oils [63]. For skin rejuvenation, microemulsion based gels with resveratrol were designed in a new study using a mixture of vegetable oils like tea tree oil and medium chain triglyceride. The reduced particle dimension under $50 \mathrm{~nm}$ along with the use of gel matrix generators can be considered variables which will contribute to the promotion of a superior release at skin site [17]. The present study is focused on the formulation, preparation, and evaluation of two groups of microemulsions as suitable vehicles for topical administration in acne pathology. Topical administration at skin site is considered by patients a well-accepted route, being proposed as a primary route in the treatment of uncomplicated dermatologic disorders or a secondary route for adjuvant local treatments beside systemic therapy $[9,42]$. Acne vulgaris is defined as a chronic, inflammatory, long-term disorder of the sebaceous glands, affecting most of the patients in the youth period, with a high number of relapses found in the adulthood [38, 59]. The multifactorial character and the complexity of pathological patterns developed at skin site, offer a great challenge in the treatment of acne [38]. In the same time, a second challenge comes from the area of drug development, considering favourable the projection of novel colloidal systems like microemulsions. These systems can surpass the cutaneous barrier of stratum corneum by targeting lipophilic actives at the affected site. For acne alleviation, various molecules were entrapped in microemulsion systems. Their optimized composition can promote superior delivery compared with conventional formulations [58]. Here, the association between $\mathrm{S}$ and $\operatorname{CoS}$ will assure supplementary disruptive effects at cellular level, due to their property of penetration enhancement [69]. To assure a safe treatment at skin area which is known as a reactive tissue at the contact with chemical substances, the use of naturalderived, biocompatible excipients, represents an outstanding interest in microemulsion formulation. Subsequently, the decrease of the total amount of tensioactive mixture, which is usually selected in large concentrations, and the introduction of biopolymers, can assure valuable characteristics for the final product [15, 20, 22]. As an oil phase, vegetable oils are appreciated as an alternative to synthetic ones, offering additional properties based on their composition, resulting personalized formulations [2, 16, 21, 22].

For our O/W topical microemulsions was chosen a biocompatible mixture of surfactants composed of lecithin and Tween 80, associating PG as a multifunctional cosurfactant. The mixture was able to solubilize the API (SA). Distilled water prepared with HA $1 \%$ was considered the continuous phase, then a mixture of vegetable oils was added using oil titration method. 
As a natural surfactant with amphiphilic properties and an HLB of 4-6, lecithin can be easily incorporated in microemulsions after a proper milling in the preparation stage $[45,64]$. Selected in small concentrations between $1 \%$ and $20 \%$, lecithin can be used for both $\mathrm{W} / \mathrm{O}$ or $\mathrm{O} / \mathrm{W}$ microemulsions, but in the last case, the association of a second surfactant must be considered in order to obtain the required HLB $[43,66]$. Xuan et al. reported the use of lecithin 5\% to create various microemulsion based gel formulations [67]. Paolino et al. considered lecithin $19 \%$ suitable to create $\mathrm{O} / \mathrm{W}$ microemulsions for ketoprofen delivery with a superior safety profile than cream and gel formulations [43]. Lecithin contains a high amount of phosphatidylcholine which will assure special additional properties in a topical formulation, and here it can be quoted few qualities like: hydrating properties and implication in penetration enhancement due to its similarity with phospholipidic domain of biomembranes [32, 60]. Likewise, non-allergic, non-immunogenic and biodegradability attributes, assure the creation of a complex pattern that may contribute to the biocompatibility character of a topical microemulsion [49, 52]. Considering the process of ME development, it can be suggested that lecithin can be combined with Tween 80 as a second surfactant to assure a proper dispersion of oil droplets due to its HLB of 15, being frequently selected in ME formulation. In addition, lecithin will contribute to the decrease of Tween 80 concentration, thus the microemulsions will no longer require higher amounts of synthetic surfactants [47]. Several studies were designed in a comparative manner to demonstrate the efficacy of Tweens in microemulsion preparation and properties concerning oil dispersion and solubilization [13]. Thus, isopropyl palmitate microemulsions were designed and analysed using successively Tween 20, Tween 40, Tween 60 and Tween 80. Tween 80 was found to be suitable to assure a superior dispersion profile for the designed systems [10]. Its high potency for oil dispersion and solubilization is correlated with its structure peculiarities, which consist in the presence of an oleic acid chain as a grafted radical on the sorbate structure [1, 39].

Propylene glycol will increase the flexibility at the $\mathrm{O} / \mathrm{W}$ interface resulting thus a complex interfacial layer [27]. Its activity as a penetration enhancer [31], solubilizer and wetting agent are studied and revealed over microemulsion evaluation in numerous research contributions $[23,65]$.

An oil phase composed of two vegetable oils rich in fatty acids may have positive effects in acne prone skin. As we suggested in our previous study, according with the literature evidence [57], oat oil and pomegranate oil were selected.

$\mathrm{O} / \mathrm{W}$ microemulsions can be considered suitable to entrap two opposite active ingredients. HA low molecular weight type (LMW) can be gently dispersed in water, due to its hydrophilicity, assuring a superior quality profile by forming new polymer-like networks at the contact with water molecules $[6,54]$. Salicylic acid as an active ingredient with keratoplastic action in a small concentration up to $1 \%$ is notably recognized for its effects in dermatologic disorders [5]. In acne pathology, SA can exert a double mechanistic action at skin level expressed as a decrease of lipid production, with a reduction of inflammatory events responsible for typical skin erythema [14, 37]. Observed from a physicochemical point of view, SA encounters formulation challenges which are attributed to its poor solubility in water [28]. However, a sophisticated but simple-to-prepare microemulsion system can solve this formulation obstacle due to the presence of S/CoS/Oil phase combination, without the need to appeal to other co-solvents like ethanol which can be unfriendly with the affected skin [35]. Muchmore, SA included in the core of intramicellar solubilized oil particles will be protected from degradative reactions [7]. In this direction, recent attempts were cantered on the development of salicylic acid MEs with keratolytic properties able to solubilize the API up to $12 \%$. Badawi et al. developed microemulsions with $2-10 \%$ salicylic acid in a microemulsion vehicle composed of isopropyl myristate $35 \%$, water $20 \%$ and a mixture of Tween 80 and PG $45 \%$. The API was successfully solubilized in the oil phase, resulting stable systems on a period of 6 months [7]. A common direction was followed by Aljamal et $a l$. in a study focused on microemulsion formulation with salicylic acid $12 \%$ and lactic acid $4 \%$ [3]. It was demonstrated also that the selection of PG is essential for the incorporation of oil phase in the system, with the possibility to embed a large concentration of lipophilic actives [3, 24].

On this way, the present study was designed in two stages of formulation and preparation, resulting two groups of microemulsions. In the first stage, four systems were designed with the aim to study the influence of lecithin concentration on the generation of O/W MEs. A domain of $0.5-2 \%$ lecithin was proposed as a part of a mixture with Tween 80 and PG in a maximum concentration of $31 \%$. Only one ME with $0.5 \%$ lecithin was considered appropriate to be selected as a model system in the second stage, where various levels of tensioactive mixtures between $30.5 \%$ and $60.5 \%$ were screened as potential solubilizers for SA $0.5 \%$. In both groups, an influence of formulation factors on the generation of MEs and their physical properties were studied by proposing hereinafter the following evaluation methods: organoleptic analysis, conductivity assessments, $\mathrm{pH}$ determinations and refractive index analysis. The results were presented in a comparative manner. For the second group of MEs, a pseudoternary phase diagram completed our preliminary data concerning formulation step, by depicting stability areas. A suggestive and complementary rheological study for three fluid systems offered a 
preliminary dataset concerning stability, internal structure, and quality, which were thought to be of high importance in discovery process of topical MEs.

\section{Materials and Methods}

\section{Materials}

The reagents and APIs used in the preparation of microemulsions were the following: granular soy lecithin $\left(S_{1}\right)$ was purchased from Acrōs Organics (Thermo Fischer Scientific, USA), Tween $80\left(\mathrm{~S}_{2}\right)$ from Roth $\mathrm{GmbH}+\mathrm{CoKG}$ (Germany) and propylene glycol (CoS or PG) from Sigma Aldrich (Germany). Natural oat oil was achieved from BioPur (Romania), while pomegranate oil and hyaluronic acid low molecular weight (HA LMW) were purchased from Elemental (Romania). Salicylic acid (SA) was supplied from Chemical Company (Romania). Distilled water was used as a continuous phase.

\section{Methods}

Formulation and preparation data for microemulsions The present experimental work was conducted in two stages of formulation-preparation, resulting two groups of microemulsions as it can be described in what follows.

First stage: Preparation of biocompatible O/W microemulsions using vegetable oils, HA LMW, with lecithin as a natural surfactant in association with a Tween 80/PG mixture. Beside the common mixture of tensioactives used in microemulsion design, lecithin can be added. In this direction, were selected four percentual levels of lecithin: $0.5 \%, 1 \%, 1.5 \%$ and $2 \%$, then only one was chosen in the second stage as function of the systems characteristics. Subsequently, it was applied the oil titration method [57], considering the following preparation approach by reporting to $20 \mathrm{~mL}$ of final product, as it can be seen in the formulation data exposed in Table I. Thus, the proper amount of lecithin was weighed at the analytical balance and placed in a mortar. It was dispersed in a half of distilled water at $42^{\circ} \mathrm{C}$ by a gentle homogenization resulting a yellowish, opalescent suspension. In a dried vial was prepared a mixture with HA previously weighed at the analytical balance and the rest of the water, resulting a viscous solution which was subjected to magnetic stirring. Simultaneously, it was prepared a mixture of Tween 80 and PG which was added gradually under lecithin suspension. The mixture became homogeneous and transparent being titrated drop by drop through the HA solution, under continuous stirring. The final clear mixture was titrated with oil phase mix (oat oil and pomegranate oil in the ratio 1:1), resulting four systems, coded MEL 1 - MEL 4, with different clarity grades which after one hour of stirring were placed in a $24 \mathrm{~h}$ resting period for equilibration.

Second stage: Starting from MEL 1 composition, there were prepared further biocompatible $O / W$ microemulsions with SA, using vegetable oils, HA LMW, considering a tensioactive mixture formed with lecithin, Tween 80 and $P G$ in a ratio of 2:1. For the second stage of experimental work, all the preparation steps were respected as well as in the first stage. Lecithin $0.5 \%$ was selected to be included in the second group. In addition, SA $0.5 \%$ was solubilized in the tensioactive mixture. According with the formulation data exposed in Table II, five microemulsions, coded MEAS 1 - MEAS 5 were obtained and equilibrated for $24 \mathrm{~h}$.

Formulation data for microemulsions prepared in the first stage, with different concentrations of lecithin in the

Table I range $0.5-2 \%$, maintaining a constant level of $\mathrm{S}_{1} / \mathrm{S}_{2} / \mathrm{CoS}$ mix of $31 \%$

\begin{tabular}{|c|c|c|c|c|c|c|}
\hline Formulation & $\begin{array}{c}\text { Lecithin } \\
(\mathbf{g \%})\end{array}$ & $\begin{array}{c}\text { Tween 80 } \\
(\mathbf{m L \%})\end{array}$ & $\begin{array}{c}\text { PG } \\
(\mathbf{m L} \text { \%) }\end{array}$ & $\begin{array}{c}\text { Oil } \\
(\mathbf{m L} \text { \%) }\end{array}$ & $\begin{array}{c}\text { Water } \\
(\mathbf{m L \%})\end{array}$ & $\begin{array}{c}\text { HA } \\
(\mathbf{g \%})\end{array}$ \\
\hline MEL 1 & 0.5 & 20.5 & 10 & 1 & 67 & 1 \\
\hline MEL 2 & 1 & 20 & 10 & 1 & 67 & 1 \\
\hline MEL 3 & 1.5 & 19.5 & 10 & 1 & 67 & 1 \\
\hline MEL 4 & 2 & 19 & 10 & 1 & 67 & 1 \\
\hline
\end{tabular}

The amounts of lecithin and hyaluronic acid were reported to $100 \mathrm{~mL}$ microemulsion

Table II

Formulation data for microemulsions prepared in the second stage, with salicylic acid $0.5 \%$, using lecithin at a constant level of $0.5 \%$ as a part of the total amount of $\mathrm{S}_{1} / \mathrm{S}_{2} / \mathrm{CoS}$ mix screened in the rage $30.5 \%-60.5 \%$

\begin{tabular}{|c|c|c|c|c|c|c|c|}
\hline Formulation & $\begin{array}{c}\text { Lecithin } \\
\text { g\% }\end{array}$ & $\begin{array}{c}\text { Tween } 80 \\
\text { mL \% }\end{array}$ & $\begin{array}{c}\text { PG } \\
\text { mL\% }\end{array}$ & $\begin{array}{c}\text { Oil } \\
\text { mL\% }\end{array}$ & $\begin{array}{l}\text { Water } \\
\text { mL \% }\end{array}$ & $\begin{array}{l}\text { HA } \\
\text { g\% }\end{array}$ & $\begin{array}{l}\text { SA } \\
\text { g\% }\end{array}$ \\
\hline MEAS 1 & 0.5 & 20 & 10 & 1 & 67 & 1 & 0.5 \\
\hline MEAS 2 & 0.5 & 25 & 12.5 & 1 & 59.5 & 1 & 0.5 \\
\hline MEAS 3 & 0.5 & 30 & 15 & 1 & 52 & 1 & 0.5 \\
\hline MEAS 4 & 0.5 & 35 & 17.5 & 1 & 44.5 & 1 & 0.5 \\
\hline MEAS 5 & 0.5 & 40 & 20 & 1 & 37 & 1 & 0.5 \\
\hline
\end{tabular}

The amounts of lecithin, hyaluronic acid and salicylic acid were reported to $100 \mathrm{~mL}$ microemulsion 
Pseudoternary phase diagram design

For the second group of MEs, stability points of microemulsions were graphically established after the design of pseudoternary phase diagram, considering the proportion of three main components: $\mathrm{S}_{1} / \mathrm{S}_{2} / \mathrm{CoS}$ mix, the oil phase, and the water phase. Triplot 4.1.2 software was used for detection of stability points and the prediction of a specific area for microemulsion generation, helping us to avoid emulsion in particular areas or zones of instability phenomena.

\section{Physical characterization of microemulsions}

Organoleptic analysis represents the first step in the physical characterization of microemulsions, resulting important clues concerning: the aspect, colour, odour and visualization of possible phase separations as a sign of instability phenomena [57].

Conductivity analysis. Conductometry is considered an essential and accessible tool used in the lab to describe fluid pharmaceutical formulations containing substances with ionization properties in an aqueous medium with electrical conductivity properties [57]. In the case of microemulsions, phase behaviour was analysed along with the influence of formulation factors for each sample at $23 \pm 0.5^{\circ} \mathrm{C}$, using Consort C901 bench conductivity meter (De Bruyne Instruments, Belgium), equipped with a platinum electrode. The measurements were realized in triplicate.

$p H$ determinations. $\mathrm{pH}$ determinations at $23 \pm 0.5^{\circ} \mathrm{C}$ were performed in order to sustain the stability of formulations, being in the same manner a quality and safety parameter for a topical product [57]. It was used Cole Parmer pH-meter bench 05943-00, -05 model (Chicago, Illinois, USA), equipped with an $\mathrm{Ag} / \mathrm{AgCl}$ electrode which was calibrated with a potassium chloride solution at pH 7 and a calibration solution for $\mathrm{pH} 4$. The measurements were realized in triplicate.

Refractive index determinations. Refractive index was measured at $23 \pm 0.5^{\circ} \mathrm{C}$ for each microemulsion, proving the clarity grade and their isotropic nature [61]. The determinations were performed using a KRÜSS DR 201-95 digital refractometer (Kruss Optronic $\mathrm{GmbH}$, Hamburg, Germany). Distilled water with a refractive index of 1.3330 was used as a reference substance.

Rheological evaluation was performed for the most representative systems, offering information concerning the phase behaviour, the quality profile and the flow characteristics according with their composition. Thus, MEAS 1 - MEAS 3 microemulsions were evaluated at $23 \pm 0.5^{\circ} \mathrm{C}$ using Multi Visc rheometer (Fungilab SA, Barcelona, Spain), equipped with an LCP spindle, as it was previously reported [26].

\section{Results and Discussion}

Practical observations concerning the formulation and preparation steps. The main direction of the topical therapy is defined by the release of the API in the epidermis and dermis structures, by avoiding the systemic absorption [11]. For lipophilic substances which are almost retained at the level of stratum corneum, ME systems represents a valuable modern formulation that can surpass the diffusional barrier due to their composition. Hence, our previous preliminary study was based on the development of O/W MEs with HA LMW, using a mixture of Tween $80 / \mathrm{PG}$ on a large domain from $55 \%$ to $75 \%$ and two minimal concentrations of oil phase $1 \%$ and $2 \%$ respectively. A microemulsion model with a high clarity grade was obtained considering the following formula: Tween 80 $32.5 \%$, PG 32.5\%, Water 33\%, Oil 1\% and HA $1 \%$ [57]. It was considered that the selection of the surfactant and cosurfactant in an adequate proportion remains an important formulation factor for the generation of MEs. Tween 80 , as a synthetic and non-ionic surfactant is preferred in topical systems due to its high power of dispersion. PG will assure the dispersion process of oil particles by increasing the fluidity and the flexibility of the interfacial layer [68]. After all, the use of synthetic surfactants will not be a formulation priority in the future anymore. Therefore, an enlargement of the perspectives in the use of natural by products with superficial activity must be taken under attention. In the same manner, some objectives were established being considered of high importance: the use of a natural surfactant that can contribute to a diminishing of the total amount of $\mathrm{S} / \mathrm{CoS}$ mixture; finding a minimum concentration of $S_{1} / S_{2} / C o S$ that can generate microemulsions; analysing the dispersion properties of lecithin in $\mathrm{O} / \mathrm{W}$ microemulsion design; the use of a minimal concentration of a combination of vegetable oils as an oil phase; introducing a biopolymer that can sustain the quality profile, but also a therapeutic effect for the vehicles after the entrapping of salicylic acid.

Thus, the first stage of the present study was based on a screening method of a proper concentration of lecithin from the range $0.5-2 \%$. It is known that the emulsification process in emulsions is associated with the tendency of lecithin to create liquid crystalline structures, which means that lecithin must be combined with a second surfactant, resulting a mixture with (micro)emulsifying properties [55]. A recent experimental study sustained the properties resulted from the combination of lecithin with Tween 20 as a tensioactive mixture for peppermint oil and Q10 coenzyme solubilization [13]. Considering these statements, Tween 80 was chosen due to its hydrophilic character and an HLB value smaller than in Tween 20 case, being able to efficiently solubilize oil particles. Considering the HLB values as 15 for Tween 80 and 5 for lecithin, will be obtained a new HLB value which will be specific for $\mathrm{O} / \mathrm{W}$ microemulsion generation. Thus, the microemulsions with lecithin from the first stage (MELs) had HLB values in the range 14.74 14.01. It was selected the HLB of 14.74 of MEL 1 
corresponding to $0.5 \%$ lecithin, being closed from the HLB value of Tween 80. In the case of the systems prepared in the second stage (MEASs), were obtained HLB values in the range 14.71 - 14.86. It can be remarked that the HLB values are specific for stable systems. In addition, Tween 80 was miscible with the water phase and assured the clarification of lecithin suspension. In the same manner, due to its two hydro carbonate chains, lecithin can contribute to oil phase dispersion. The HLB values for surfactant mixtures were calculated using the following formula according with de Melo Cotrim et al. work [40]:

$$
H L B_{M E}=\frac{H L B_{T w e e n ~}^{80} \cdot F_{1}+H L B_{\text {Lecithin }} \cdot F_{2}}{10-F_{C O}}
$$

where $F_{1}$ represents Tween 80 fraction, $F_{2}$ - lecithin fraction, and $\mathrm{F}_{\mathrm{CO}}-\mathrm{CoS}$ fraction, while the sum $\mathrm{F}_{1}+$ $\mathrm{F}_{2}+\mathrm{F}_{\mathrm{CO}}=10$. It was presumed that the stability

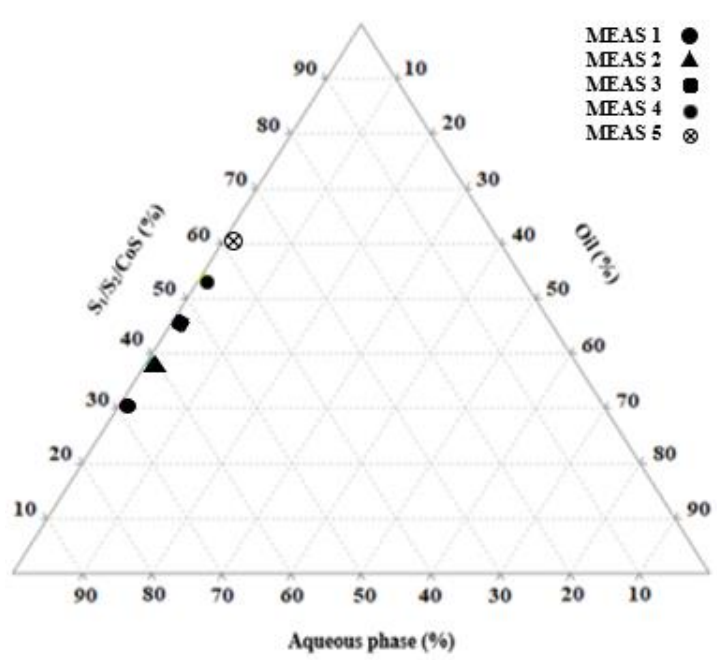

(a) induced by Tween $80 /$ lecithin/PG is similar with that of Tween 80/PG.

Pseudoternary phase diagram design. In microemulsion development, graphical design represents one of the main contributions that can sustain the characteristics of the final formulations. On the diagram can be visualized various types of systems, from clear, fluid type ones, through viscous, gel type microemulsions, always guiding a research toward the obtaining of desired formulations, accordingly with the experimental data, being also used in the optimization process [33]. For MEAS 1 - MEAS 5 systems, pseudoternary phase diagram was constructed being exposed in Figure 1, along with its section which is focused on the area of stability as function of each concentration established in the formulation design. The amount of $S_{1}, S_{2}$ and $\operatorname{CoS}$ will influence the physical characteristics of the systems, the flow behaviour and their stability in time.

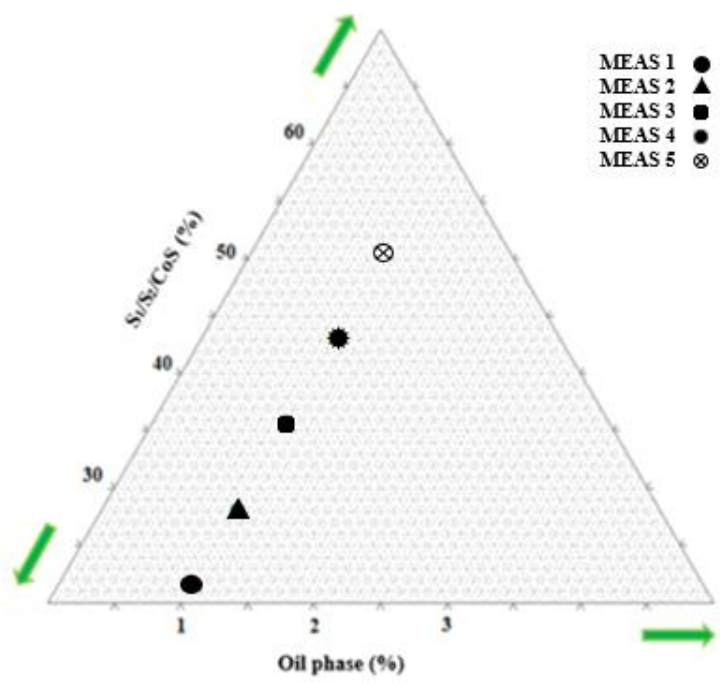

(b)

Figure 1.

Pseudoternary phase diagram for MEAS 1 - MEAS 5 systems, emphasizing the stability points (a), along with its section which encompasses the stability area by reference to the total amount of tensioactive and oil phase (b)

Organoleptic analysis. In the first stage of preparation, were designed various systems using lecithin which was suspended in water at $42^{\circ} \mathrm{C}$ and embedded in a mixture formed with Tween 80 and PG. Lecithin can modify the properties of microemulsions, including here the organoleptic ones. Thus, the knowledge of the minimum and maximum concentration that can be accessed in ME generation was important for both phases of preparation. Considering the interval of 1 $20 \%$ cited in literature, suitable for lecithin-based microemulsions, were considered four levels of lecithin concentration by maintaining a constant level of total amount of tensioactive $\left(\mathrm{S}_{1} / \mathrm{S}_{2} / \mathrm{CoS}\right)$ at $31 \%$, with a slightly variation of Tween 80 from $19 \%$ to $20.5 \%$, without changing PG concentration. According to this variation of the two surfactants, the stirring time was influenced. The dispersion time will increase proportionally with the increase of lecithin concentration from $0.5 \%$ until $2 \%$. The MEL 1 - MEL 4 systems were translucent; the transparency increased on a period of two weeks, being possible the study of refractive index. The yellow colour, the fluid appearance and the odour were specific according with their composition. The clarity of the systems was influenced by the introduction of the mixture Tween $80 / \mathrm{PG}$ drop by drop through lecithin suspension.

Tween 80 had a high influence in the dispersion process, and for the final consistency of each system. In the second part, lecithin $0.5 \%$ was associated with mixtures of Tween 80 and PG (2:1), starting from $30 \%$ up to $60 \%$. Thus, there were obtained two types of microemulsions: MEAS 1, MEAS 2, MEAS 3 as fluid and clear systems, and MEAS 4, MEAS 5 as gel-like microemulsions, where MEAS 4 had a high 
grade of transparency. Their yellow colour, odour and appearance was correlated with the composition. Over the evaluation period, the systems maintained their homogeneity and stability, without being visualized phase separations and other instability phenomena. All the prepared microemulsions were stable at room temperature $\left(23 \pm 0.5^{\circ} \mathrm{C}\right)$, and at modified temperatures $\left(4 \pm 0.5^{\circ} \mathrm{C}, 40 \pm 0.5^{\circ} \mathrm{C}\right)$.

Conductivity analysis. Conductivity values for the tested MEs were correlated with the $\mathrm{O} / \mathrm{W}$ type, being highly influenced by composition of each formulation. As it can be observed in the Table III, specific for the first stage of preparation, conductivity values varied in the range $1062.00 \pm 44.23 \mu \mathrm{S} / \mathrm{cm}-1200.00 \pm 28.82$ $\mu \mathrm{S} / \mathrm{cm}$, without being defined a strong correlation with their composition. The elevated values are specific due to the introduction of lecithin containing phosphatidylcholine fractions with two ionic groups, which can increase the electrical conductivity [4].

Conductivity values for microemulsions prepared in the first stage, MEL $1-$ MEL 4 , tested at $23 \pm 0.5^{\circ} \mathrm{C}$

\begin{tabular}{|c|c|c|c|c|c|}
\hline Formulation & $\begin{array}{c}\text { Water } \\
(\boldsymbol{\%})\end{array}$ & $\begin{array}{c}\boldsymbol{k}_{\mathbf{1}} \\
(\boldsymbol{\mu} \mathbf{S} / \mathbf{c m})\end{array}$ & $\begin{array}{c}\boldsymbol{k}_{\mathbf{2}} \\
(\boldsymbol{\mu} \mathbf{S} / \mathbf{c m})\end{array}$ & $\begin{array}{c}\boldsymbol{k}_{\mathbf{3}} \\
(\boldsymbol{\mu S} / \mathbf{c m})\end{array}$ & $\begin{array}{c}\overline{\boldsymbol{k}}(\mathbf{\pm} \mathbf{S D}) \\
(\boldsymbol{\mu} \mathbf{S} / \mathbf{c m})\end{array}$ \\
\hline MEL 1 & 67 & 1144.00 & 1253.00 & 1157.00 & $1184.66 \pm 59.53$ \\
\hline MEL 2 & 67 & 1012.00 & 1080.00 & 1095.00 & $1062.00 \pm 44.23$ \\
\hline MEL 3 & 67 & 1121.00 & 1105.00 & 1084.00 & $1103.00 \pm 18.56$ \\
\hline MEL 4 & 67 & 1231.00 & 1195.00 & 1174.00 & $1200.00 \pm 2882$ \\
\hline
\end{tabular}

Considering the data exposed in Table IV, conductivity was influenced by all the components involved in microemulsion formulation. Higher values are attributed to lecithin inclusion, but the descendent trend of values from $1021.00 \pm 11.53 \mu \mathrm{S} / \mathrm{cm}$ for MEAS 1 until $363.66 \pm$ $11.93 \mu \mathrm{S} / \mathrm{cm}$ for MEAS 5 was dependent of water and tensioactive mixture $\left(\mathrm{S}_{1} / \mathrm{S}_{2} / \mathrm{CoS}\right)$, where their evolution can be better observed in a graphical analysis in Figure 2.

$p H$ determinations. The acidic mantle of the skin exerts a protective action against bacterial and fungal proliferation, at $\mathrm{pH}$ values between 4 and 6 [34]. $\mathrm{pH}$ variation over these limits, with extensions in the basic zone is specific for acne prone skin [46]. It was followed the variation of $\mathrm{pH}$ for the two groups of microemulsions, by analysing the impact of hydrogen ions generation and the repercussions that may appear at skin level.

For MEL 1 - MEL 4 group, pH varied proportionally with the increase of lecithin concentration. The values were placed in the physiological domain, between $4.26 \pm 0.17-4.37 \pm 0.01$. It can be stated that lecithin represents a valuable ingredient implied in $\mathrm{pH}$ modulation of a topical formulation, as function of its concentration.

Conductivity values for microemulsions prepared in the second stage, MEAS 1 MEAS 5 , tested at $23.0 .3^{\circ} \mathrm{C}$

\begin{tabular}{|c|c|c|c|c|c|c|}
\hline Formulation & $\begin{array}{c}\text { Water } \\
(\boldsymbol{\%})\end{array}$ & $\mathbf{S}_{\mathbf{1}} / \mathbf{S}_{\mathbf{2}} / \mathbf{C o S}(\boldsymbol{\%})$ & $\boldsymbol{k}_{\mathbf{1}}(\boldsymbol{\mu S} / \mathbf{c m})$ & $\begin{array}{c}\boldsymbol{k}_{\mathbf{2}} \\
(\boldsymbol{\mu S} / \mathbf{c m})\end{array}$ & $\begin{array}{c}\boldsymbol{k}_{\mathbf{3}} \\
(\boldsymbol{\mu S} / \mathbf{c m})\end{array}$ & $\begin{array}{c}\overline{\boldsymbol{k}}(\mathbf{\pm} \mathbf{S D}) \\
(\boldsymbol{\mu S} / \mathbf{c m})\end{array}$ \\
\hline MEAS 1 & 67 & 30.5 & 1034.00 & 1017.00 & 1012.00 & $1021.00 \pm 11.53$ \\
\hline MEAS 2 & 59.5 & 38 & 843.00 & 827.00 & 822.00 & $830.66 \pm 10.96$ \\
\hline MEAS 3 & 52 & 45.5 & 579.00 & 550.00 & 533.00 & $554.00 \pm 23.26$ \\
\hline MEAS 4 & 44.5 & 53 & 397.00 & 390.00 & 382.00 & $389.66 \pm 7.67$ \\
\hline MEAS 5 & 37 & 60.5 & 377.00 & 354.00 & 360.00 & $363.66 \pm 11.93$ \\
\hline
\end{tabular}

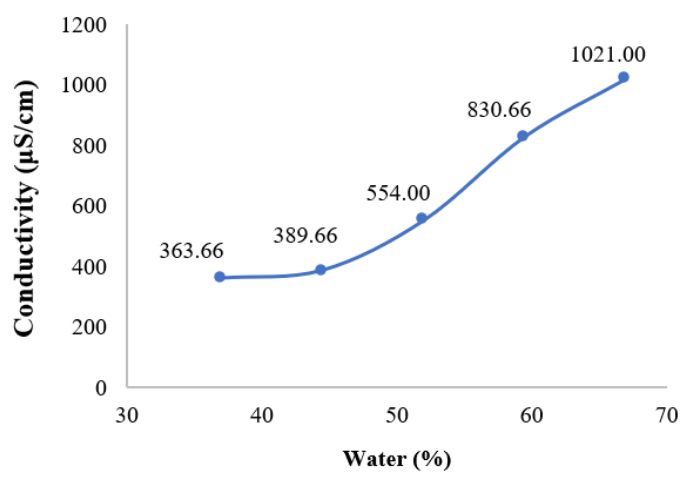

(a)

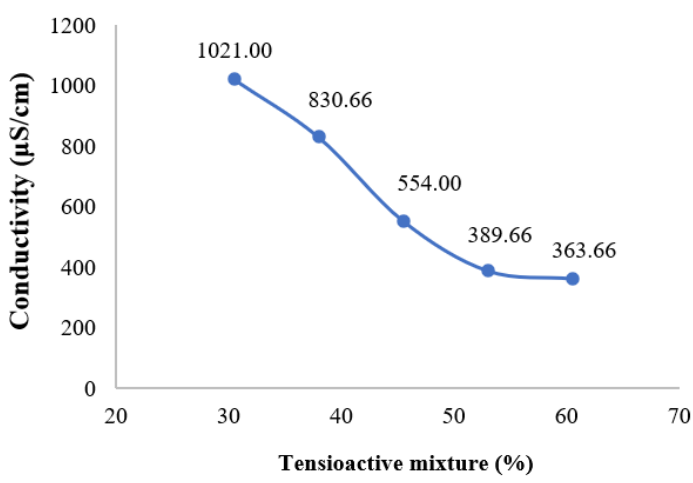

(b)

Figure 2.

Graphical representations of conductivity variation for MEAS 1 - MEAS 5 systems at $23 \pm 0.5^{\circ} \mathrm{C}$, as function of water content (a) or tensioactive mixture content (b) 
In the case of MEAS 1 - MEAS 5 systems, $\mathrm{pH}$ values were smaller than in the anterior case. The presence of salicylic acid increases the concentration of hydrogen ions in the ME medium, being measured $\mathrm{pH}$ values between $3.57 \pm 0.01-4.13 \pm 0.01$. On the other hand, tensioactive mixture can sustain a correction of $\mathrm{pH}$, by placing it around the physiological domain, avoiding in this way undesirable irritative effects. In Figure 3, are presented variations of $\mathrm{pH}$ as function of lecithin

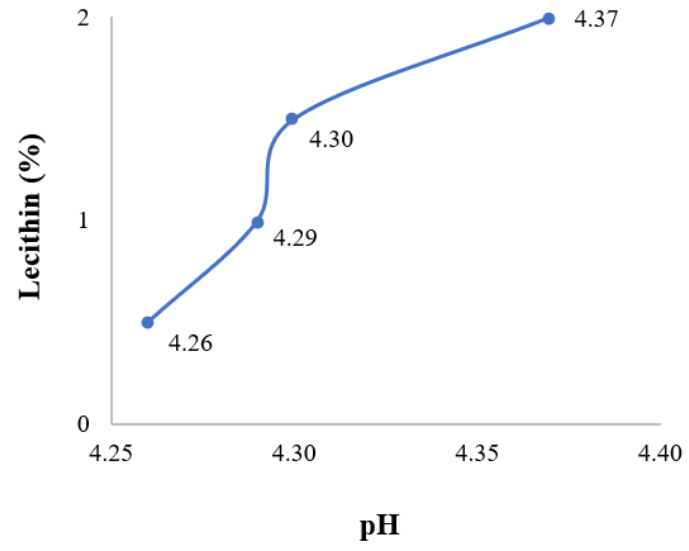

(a) amount for the first group of MEs, as well as function of the total amount of $\mathrm{S}_{1} / \mathrm{S}_{2} / \mathrm{CoS}$ mix for the second group. Actual researches have explained the influence of $\mathrm{pH}$ in acne patterns, demonstrating that a $\mathrm{pH}$ placed in the acidic domain around 4, can reduce the inflammatory response, with positive implications in keratinization regulation and regenerative processes [46].

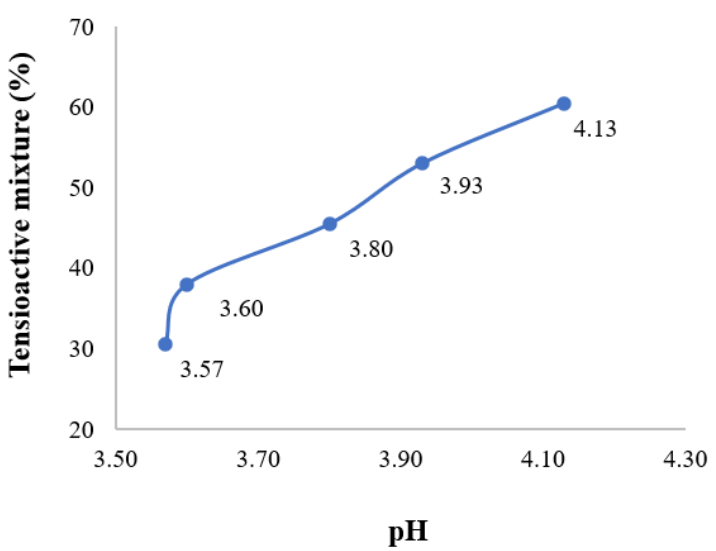

(b)

Figure 3.

Graphical representations of $\mathrm{pH}$ variation for the two groups of systems, tested at $23 \pm 0.5^{\circ} \mathrm{C}$ : MEL $1-\mathrm{MEL} 4$ $\mathrm{pH}$ values as function of lecithin content (a), and MEAS 1 - MEAS $5 \mathrm{pH}$ values as function of the total amount of tensioactive mixture (b)

Refractive index determinations. Refractive index (RI) represents a physical and quality parameter that was highly influenced by the composition of microemulsions. The literature evidence quotes microemulsions as clear, sometimes translucent, isotropic systems, being a resultant of the dispersion process of particles at a nanometric level. For the first group, refractive index varied in the domain 1.3766 - 1.3867. A diminishing in clarity was observed for MEL 2 ( $\mathrm{n}=$ 1.3867). On the other side, in the second group, refractive index was influenced by water concentration and Tween 80/PG mixture. Tailoring these formulations using MEL 1 as a model system, lead to new systems with refractive index between 1.3749 for MEAS 1 with the maximum amount of water of $67 \%$ and a low level of Tween 80/PG of 30\%, and 1.4081 for MEAS 5 with a low amount of water of $37 \%$ and a high level of tensioactive of $60.5 \%$. In Figure 4, it was represented the variation of refractive index as function of water content for the second group of MEs. The highest values were depicted for MEAS 4 and
MEAS 5 with a gel-like appearance. The addition of SA didn't affect the isotropy of microemulsions.

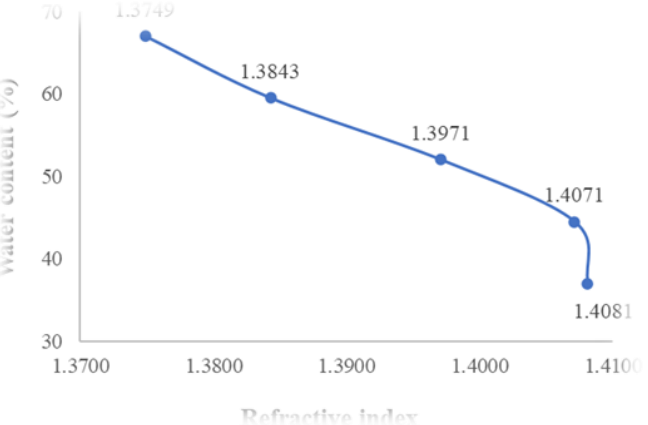

Figure 4.

Refractive index data, represented as function of water content for MEAS 1 - MEAS 4 systems

Rheological evaluation. Rheological evaluation was conducted in order to assess the flow behaviour of the fluid-like microemulsions from the second stage of the study.

Table V

Mathematical modelling of the rheological profiles and viscosity values for MEAS 1 - MEAS 3 systems

\begin{tabular}{|c|c|c|c|}
\hline Formulation & Straight line equation & Determination coefficient & Viscosity $(\mathbf{c P})$ \\
\hline MEAS 1 & $\mathrm{y}=0.0315 \mathrm{x}-0.0075$ & 0.9994 & 31.5 \\
\hline MEAS 2 & $\mathrm{y}=0.0788 \mathrm{x}+0.0605$ & 0.9994 & 78.8 \\
\hline MEAS 3 & $\mathrm{y}=1.3173 \mathrm{x}+0.4866$ & 0.9996 & 1317.3 \\
\hline
\end{tabular}




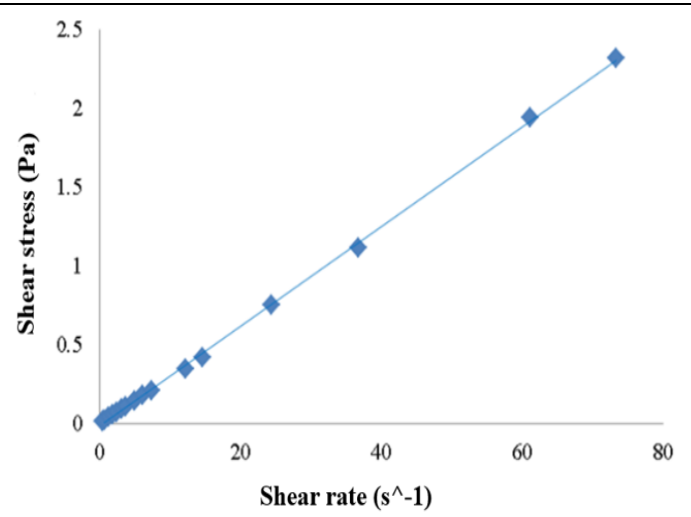

(a)

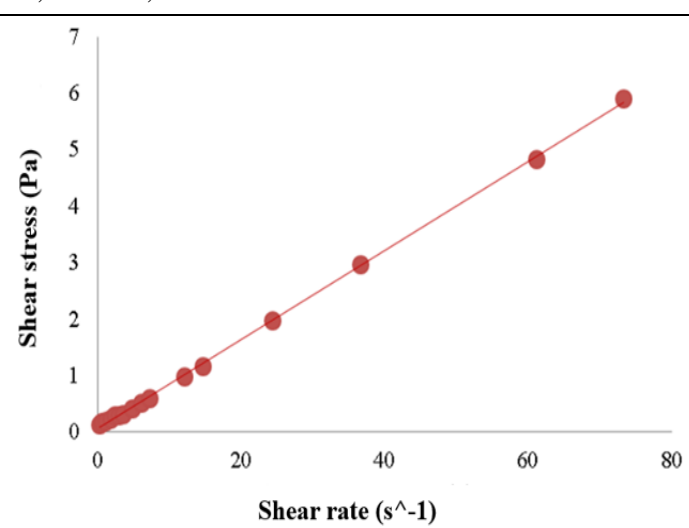

(b)

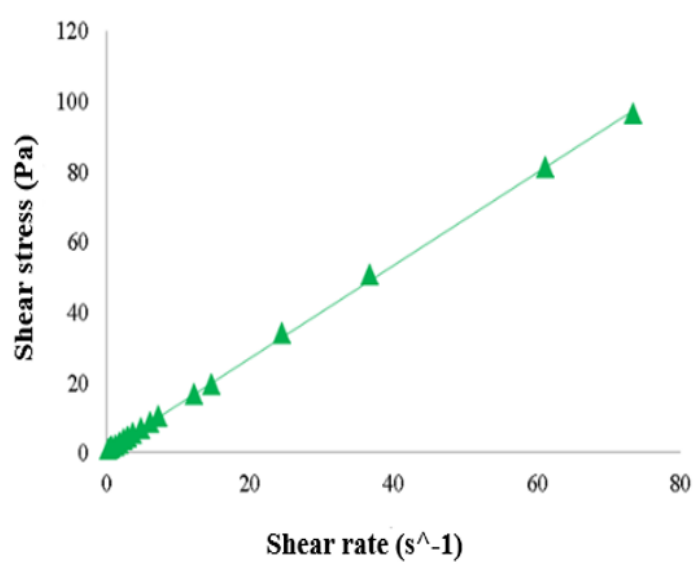

(c)

Figure 5.

Rheological profiles for fluid microemulsions: (a) MEAS 1; (b) MEAS 2; (c) MEAS 3

For MEAS 1 - MEAS 3 systems, plots of shear stress $(\mathrm{Pa})$ as function of shear rate $\left(\mathrm{s}^{-1}\right)$ were represented, being characterized by straight line equations and their determination coefficients (Table V). Graphical representations are illustrated in the Figures 5a - 5c. As can be remarked from Table $\mathrm{V}$ and from rheological profiles (Figure 5) for each formulation, viscosity was maintained at a constant level without modification on the period of shear stress and shear rate variation. Thus, it was concluded that microemulsions, as function of their composition are fluid structures with a Newtonian behaviour, according to the Newton's law. Concerning the characteristics of the evaluated systems, the inclusion of Tween 80/PG and the diminishing of the water content affect the viscosity, being visualized values of dynamic viscosity in the range $31.5 \mathrm{cP}$ $1317.3 \mathrm{cP}$ for MEAS 1 - MEAS 3 systems, as it shown Table V. It was interesting to observe that an increase of Tween 80 from $20 \%$ to $25 \%$ and PG respectively, from $10 \%$ to $15 \%$ produced a moderate modification in flow behaviour, increasing the viscosity of MEAS 2 by 2.5 folds, compared to MEAS 1 . On the other hand, an elevation of Tween 80 from $20 \%$ to $30 \%$, and of PG from $10 \%$ to $20 \%$, produced an increase of viscosity specific for MEAS 3 by 40 folds. Over this limit, the increase of Tween 80 and PG, keeping the same ratio of $2: 1$, and decreasing the water content, determined the generation of microemulsion based gels for which a special attention will be accorded in further studies. Salicylic acid can be responsible for a smaller value of viscosity in the case of MEAS 1 compared with MEAS 2 and MEAS 3, where the amount of Tween 80/PG was increased. Several studies reported the impact of APIs on the flow behaviour for microemulsions with salicylic acid or terconazole [7, 56]. Extensive studies may be performed in this direction concerning inclusively the influence of tensioactive concentration at higher levels in the generation of gel-like structures and their internal behaviour. As a final remark, HA and the tensioactive mixture influenced the viscosity of the formulations, offering a favourable consistency for topical application and a proper displaying of the product on the affected skin area. Furthermore, HA can be considered a polymer that induce a primary viscosity background for the systems. At the contact with water molecules was formed a polymeric network 
generated by hydrogen bonding chains, compatible with all the reagents used in the preparation process. It can be appreciated that rheological parameters can be highly influenced by systems composition as well as in the case of the anterior results of conductivity, $\mathrm{pH}$ and refractive index. The present study, with a generous template of information concerning the formulation and preparation parameters, was planned as a preliminary study, emphasizing the fundamentals of microemulsion design as a part of a condensed group of microsystems suitable for topical application in the treatment of dermatologic conditions.

\section{Conclusions}

As final remarks, microemulsions can be considered suitable vehicles for topical administration of dermatologic drugs. Microemulsions are appreciated for several qualities like thermodynamic stability, high solubilization power and versatility in the process of excipients selection. Their internal structure has high influence on the entrapment process of molecules with different physicochemical profiles and formulation challenges. Our preliminary study defined a valuable method to formulate and prepare topical microemulsions with hyaluronic acid and salicylic acid, using biocompatible ingredients with the aim to find a minimal concentration of tensioactive mixture that can generate stable microemulsions. According to the evaluation performing, were screened combinations of lecithin/Tween 80/PG $31 \%$ as mixtures with potential for API solubilization and small quantities of vegetable oils. For the second level of screening, MEL 1 with $0.5 \%$ lecithin was considered a model system. As a result, a group of five MEs MEAS 1 - MEAS 5 delimited stable systems with salicylic acid, with fluid and gel-like appearance. It was discovered the minimal concentration of tensioactives of $30.5 \%$ that can be introduced as a promotor for clear and stable MEs. Furthermore, conductivity was specific for $\mathrm{O} / \mathrm{W}$ systems, while $\mathrm{pH}$ confirmed their safety profile for topical application, being observed a strong correlation with the composition. Refractive index analysis proved their isotropy, introducing on this way fundamental concepts concerning colloids (micro- or nano-coloids) and clues about their dimension which are of interest in future studies. Phase diagram for MEAS 1 - MEAS 5 systems was completed using graphical design, emphasizing the influence of formulation factors for the stability and pharmaceutical relevance of the projected microemulsions. Only for the formulations coded as MEAS 1 - MEAS 3, Newtonian behaviour was found to be specific, with variations conditioned by their internal structure which was dependent of composition. The study offered important preliminary data concerning microemulsion formulation, paving the way through an expansion of experimental domain and proposing more specific stability assays in prospective studies.

\section{Acknowledgement}

This work was financially supported by CNFISFDI-2021-0300, RDI capabilities consolidation at Institutional level of the multidisciplinary research teams involved in the sustainability of UMFCD priority research directions.

\section{Conflict of interest}

The authors declare no conflict of interest.

\section{References}

1. Abd-Allah FI, Dawaba HM, Ahmed AM, Development of a microemulsion-based formulation to improve the availability of poorly water-soluble drug. Drug Discov Ther., 2010; 4(4): 257-266.

2. Al Hanadi J, Popescu C, Udeanu DI, Arsene A, Sevastre A, Velescu BȘ, Lupuliasa D, Comparative study regarding the physico-chemical properties and microbiological activities of Olea europaea L. oil and Cannabis sativa L. seed oil obtained by cold pressing. Farmacia, 2019; 67(5): 759-763.

3. Aljamal M, Kayali I, Abul-Haj M, Topical salicylic acid and lactic acid microemulsion. OMCIJ, 2017; 2(3): 1-5.

4. Anicescu MC, Dinu-Pîrvu CE, Ghica MV, Anuța V, Prisada RM, Talianu MT, Popa L. Preliminary analysis of emulsion-based formulations containing pumpkin seed oil and hemp seed oil for internal use. In: Proceedings of the $8^{\text {th }}$ International Conference of Advanced Materials and Systems, Coară G, Alexandrescu L, (Eds.), Certex Publishing: Bucharest, 2020; 115 120.

5. Arif T, Salicylic acid as a peeling agent: a comprehensive review. Clin Cosmet Investig Dermatol., 2015; 8: 455-461.

6. Asari A, Medical Application of hyaluronan. In: Chemistry and Biology of Hyaluronan, Garg HG, Hales CA, (Eds.), Elsevier Science Ltd: Oxford, 2004; 457-473.

7. Badawi AA, Nour SA, Sakran WS, El-Mancy SMS, Preparation and evaluation of microemulsion systems containing salicylic acid. AAPS PharmSciTech., 2009; 10(4): 1081-1084.

8. Badruddoza AZM, Gupta A, Myerson AS, Trout BL, Doyle PS, Low energy nanoemulsions as templates for the formulation of hydrophobic drugs. Adv Ther., 2018; 1(1), 17000020: 1-8.

9. Bagel J, Gold LS, Combining topical psoriasis treatment to enhance systemic and phototherapy: a review of the literature. J Drugs Dermatol., 2017; 16(12): 12091222.

10. Basheer HS, Noordin MI, Ghareeb MM, Characterization of microemulsions prepared using isopropyl palmitate with various surfactants and cosurfactants. Trop $J$ Pharm Res., 2013; 12: 305-310.

11. Benson HAE, Grice JE, Mohammed Y, Namjoshi S, Roberts MS, Topical and transdermal drug delivery: from simple potions to smart technologies. Curr Drug Deliv., 2019; 16(5): 444-460.

12. Callender SP, Mathews JA, Kobernyk K, Wettig SD, Microemulsion utility in pharmaceuticals: implications 
FARMACIA, 2021, Vol. 69, 3

for multi-drug delivery. Int J Pharm., 2017; 526(1-2): 425-442.

13. Chen H, Guan Y, Zhong Q, Microemulsions based on a sunflower lecithin-Tween 20 blend have high capacity for dissolving peppermint oil and stabilizing coenzyme Q10. J Agric Food Chem., 2015; 63(3): 983-989.

14. Christine JC, Arambula K, Chon S, Kimball, A doubleblind comparison of the efficacy of a salicylic acid based acne treatment regimen versus a benzoyl peroxide based acne treatment regimen for the treatment of acne vulgaris. J Am Acad Dermatol., 2004; 50(3): P13.

15. Corrias F, Dolz M, Herraez M, Diez-Sales O, Rheological properties of progesterone microemulsions: influence of xanthan and chitosan biopolymer concentration. J Appl Polym Sci., 2008; 110(2): 1225-1235.

16. Dănilă E, Moldovan Z, Albu Kaya MG, Ghica MV, Formulation and characterization of some oil in water cosmetic emulsions based on collagen hydrolysate and vegetable oils mixtures. Pure Appl Chem., 2019; 91(9): 1493-1507.

17. Das S, Lee SH, Chow PS, Macbeath C, Microemulsion composed of combination of skin beneficial oils as vehicle: development of resveratrol-loaded microemulsion based formulations for skin care applications. Colloids Surf B Biointerfaces, 2020; 194: 111161: 1-12.

18. Derle DV, Sagar BSH, Pimpale S, Microemulsion as a vehicle for transdermal permeation of nimesulide. Indian J Pharm Sci., 2006; 68(5): 622-625.

19. Dixit GR, Mathur VB, Microemulsions: platform for improvement of solubility and dissolution of poorly soluble drugs. Asian J Pharm Clin Res., 2015; 8(5): 7-17.

20. Farage MA, The prevalence of sensitive skin. Front Med., 2019; 6(98): 1-13.

21. Fiori KP, Torres MPR, Schons JL, Ribeiro EB, Nogueira RM, Vasconcelos LG, Andrighetti CR, Jacinto MJ, Valladão DMS, Microemulsion of Brazil nut oil as a natural product to improve superoxide release in human phagocytes. Quím Nova, 2017; 40(9): 10511057.

22. Gupta S, Sanyal SK, Datta S, Moulik SP, Preparation of prospective plant oil derived micro-emulsion vehicles for drug delivery. Indian J Biochem Biophys., 2006; 43(4): 254-257.

23. Haque T, Talukder MMU, Chemical enhancer: a simplistic way to modulate barrier function of the stratum corneum. Adv Pharm Bull, 2018; 8(2): 169179.

24. Heard CM, Ethanol and other alcohols: old enhancers, alternative perspectives. In: Percutaneous Penetration Enhancers Chemical Methods in Penetration Enhancement: Modification of the Stratum Corneum, Dragicevic N, Maibach HI, (Eds.), Springer: Berlin, Heidelberg, 2015; 151-172.

25. Heuschkel S, Goebel A, Neubert RHH, Microemulsionsmodern colloidal carrier for dermal and transdermal drug delivery. J Pharm Sci., 2008; 97(2): 603-631.

26. Irimia T, Mușat GC, Prisada RM, Ghica MV, DinuPîrvu CE, Anuța V, Velescu BŞ, Popa L, Contributions on formulation and preliminary evaluation of ocular colloidal systems of chitosan and poloxamer 407 with bupivacaine hydrochloride. Farmacia, 2019; 67(4): 702-708.
27. Ja'afar SM, Khalid RM, Othaman R, Mokhtar WNAW, Ramli S, Coconut oil based microemulsion formulations for hair care product application. Sains Malays, 2019; 48: 599-605.

28. Jouyban A, Panahi-Azar V, Khonsari F, Solubility of salicylic acid in ethanol, propylene glycol, and $\mathrm{N}$-methyl-2-pyrrolidone at various temperatures and their binary mixtures at 298.2K. J Mol Liq., 2011; 160(1): 14-16.

29. Kale S, Deore S, Emulsion micro emulsion and nano emulsion: a review. Sys Rev Pharm., 2016; 8(1): 39-47.

30. Kaptay G, On the negative surface tension of solutions and on spontaneous emulsification. Langmuir, 2017; 33(40): 10550-10560.

31. Karaman EF, Çelik B, Özdemir S, Tekkeli EK, Demirkoz AB, Gönüllü U, Üner M, Influence of vehicles and penetration enhancers on anti-inflammatory effect of 18- $\beta$ glycyrrhetinic acid: kinetic modelling of drug release, in vivo and ex vivo experiments. Farmacia, 2020; 68(4): 646-655.

32. Khode S, Lalan M, Lecithin microemulsion based systems for dermal delivery of drugs: a review. $J$ Pharm Sci Technol Mgmt., 2015; 1(1): 98-109.

33. Kumar R, Kumar S, Sinha VR, Evaluation and optimization of water-in-oil microemulsion using ternary phase diagram and central composite design. $J$ Dispers Sci Technol., 2016; 37(2): 166-172.

34. Kuo SH, Shen CJ, Shen CF, Cheng CM, Role of $\mathrm{pH}$ value in clinically relevant diagnosis. Diagnostics, 2020; 10(2), 107.

35. Lachenmeier DW, Safety evaluation of topical applications of ethanol on the skin and inside the oral cavity. J Occup Med Toxicol., 2008; 3, 26: 1-16.

36. Langevin D, Microemulsions - interfacial aspects. Adv Colloid Interface Sci., 1991; 34: 583-595.

37. Lu J, Cong T, Wen X, Li X, Du D, He G, Jiang X, Salicylic acid treats acne vulgaris by suppressing AMPK/SREBP1 pathway in sebocytes. Exp Dermatol., 2019; 28(7): 786-794.

38. Lynn DD, Umari T, Dunnick CA, Dellavalle RP, The epidemiology of acne vulgaris in late adolescence. Adolesc Health Med Ther., 2016; 7: 13-25.

39. Mehta SK, Kaur G, Bhasin KK, Tween-embedded microemulsions-physicochemical and spectroscopic analysis for antitubercular drugs. AAPS PharmSciTech., 2010; 11(1): 143-153.

40. de Melo Cotrim AC, Honorio-França AC, França $\mathrm{EL}$, Rheology analysis can be added in thermal stability test for design microemulsion materials. Biointerface Res Appl Chem., 2016; 6(2): 1128-1136.

41. Moulik SP, Paul BK, Structure, dynamics and transport properties of microemulsions. Adv Colloid Interface Sci., 1998; 78(2): 99-195.

42. Pangilinan R, Tice A, Tillotson G, Topical antibiotic treatment for uncomplicated skin and skin structure infections: review of the literature. Expert Rev Antiinfect Ther., 2009; 7(8): 957-965.

43. Paolino D, Ventura CA, Nisticò S, Puglisi G, Fresta M, Lecithin microemulsions for the topical administration of ketoprofen: percutaneous adsorption through human skin and in vivo human skin tolerability. Int J Pharm., 2002; 244(1-2): 21-31.

44. Pavoni L, Perinelli DR, Bonacucina G, Cespi M, Palmieri GF, An overview of micro- and nanoemulsions 
as vehicles for essential oils: formulation, preparation and stability. Nanomaterials, 2020; 10(1), 135.

45. Pichot R, Watson RL, Norton IT, Phospholipids at the interface: current trends and challenges. Int $J$ Mol Sci., 2013; 14(6): 11767-11794.

46. Proksch E, pH in nature, humans and skin. J Dermatol., 2018; 45(9): 1044-1052.

47. Radomska-Soukharev A, Wojciechowska J, Microemulsions as potential ocular drug delivery systems: phase diagrams and physical properties depending on ingredients. Acta Pol Pharm., 2005; 62(6): 465-471.

48. Rajpoot K, Tekade RK, Microemulsion as drug and gene delivery vehicle: an inside story. In: Advances in Pharmaceutical Product Development and Research, Tekade R, (Ed.), Academic Press (Elsevier): London, 2019; 455-520.

49. Raut S, Bhadoriya SS, Uplanchiwar V, Mishra V, Gahane A, Jain SK, Lecithin organogel: a unique micellar system for the delivery of bioactive agents in the treatment of skin aging. Acta Pharm Sin B, 2012; 2(1): 8-15.

50. Resende KX, Corrêa MA, de Oliveira AG, Scarpa MV, Effect of cosurfactant on the supramolecular structure and physicochemical properties of non-ionic biocompatible microemulsions. Rev Bras Cienc Farm., 2008; 44(1): 35-42.

51. Sabale V, Vora S, Formulation and evaluation of microemulsion-based hydrogel for topical delivery. Int J Pharm Investig., 2012; 2(3): 140-149.

52. Schuh RS, Bruxel F, Teixeira HF, Physicochemical properties of lecithin-based nanoemulsions obtained by spontaneous emulsification or high-pressure homogenization. Quím Nova, 2014; 37(7): 1193-1198.

53. Shah V, Gandhi K, Parikh R, Sharma M, Suthar V, Quality by Design (QbD) approach for optimization of microemulsion based topical gel. Marmara Pharm J., 2016; 20: 415-424.

54. Snetkov P, Zakharova K, Morozkina S, Olekhnovich R, Uspenskaya M, Hyaluronic acid: the influence of molecular weight on structural, physical, physicochemical, and degradable properties of biopolymer. Polymers, 2020; 12(8): 1800: 1-33.

55. Sramala I, Pinket W, Pongwan P, Jarussophon S, Kasemwong K, Development of an in vitro system to simulate the adsorption of self-emulsifying tea (Camellia oleifera) seed oil. Molecules, 2016; 21(5): 479: 1-9.

56. Talaat SM, Elnaggar YSR, Abdalla OY, Lecithin microemulsion lipogels versus conventional gels for skin targeting of terconazole: in vitro, ex vivo, and in vivo investigation. AAPS PharmSciTech., 2019; 20, 161: 1-20.

57. Talianu MT, Popa L, Ghica MV, Dinu-Pîrvu CE, Anicescu C, Design, formulation and evaluation studies of dermatocosmetic microemulsions based on oat oil, pomegranate oil and hyaluronic acid. In: Proceedings of The Romanian National Congress of Pharmacy, Drăgănescu D, Arsene A, (Eds.), Filodiritto: Bologna, 2018; 218-222.
58. Talianu MT, Dinu-Pîrvu CE, Ghica MV, Anuţa V, Jinga V, Popa L, Foray into concepts of design and evaluation of microemulsions as a modern approach for topical applications in acne pathology. Nanomaterials, 2020; 10(11): 2292: 1-43.

59. Tuchayi S, Makrantonaki E, Ganceviciene R, Dessinioti C, Feldman SR, Zouboulis CC, Acne vulgaris. Nat Rev Dis Primers, 2015; 1(1): 15029: 1-20.

60. Vater C, Hlawaty V, Werdenits P, Cichoń MA, Klang V, Elbe-Bürger A, Wirth M, Valenta C, Effects of lecithin-based nanoemulsions on skin: short-time cytotoxicity MTT and BrdU studies, skin penetration of surfactants and additives and the delivery of curcumin. Int J Pharm., 2020; 580: 119209: 1-10.

61. Vlaia L, Olariu I, Coneac G, Muț AM, Popoiu C, Stănciulescu C, Anghel DF, Maxim ME, Kalas S, Vlaia V, Development of microemulsion-loaded hydrogel formulations for topical delivery of metoprolol tartrate: physicochemical characterization and ex vivo evaluation. Farmacia, 2016; 64(6): 901-913.

62. Vlaia L, Coneac G, Olariu I, Muţ AM, Anghel DF, Maxim ME, Şaramet G, Mitu M, Lupuleasa D, Vlaia $\mathrm{V}$, Loratadine-loaded microemulsions for topical application. Formulation, physicochemical characterization and in vitro drug release evaluation. Farmacia, 2017; 65(6): 851-861.

63. Vlaia L, Coneac G, Muţ AM, Olariu I, Vlaia V, Anghel DF, Maxim ME, Dobrescu A, Hîrjău M, Lupuleasa D, Topical biocompatible fluconazoleloaded microemulsions based on essential oils and sucrose esters: formulation design based on pseudoternary phase diagrams and physicochemical characterization. Processes, 2021; 9(1): 1-21.

64. Weete JD, Betageri S, Griffith GL, Improvement of lecithin as an emulsifier for water-in-oil emulsions by thermalization. J Am Oil Chem Soc., 1994; 71(7): 731-737.

65. Wuttikul K, Boonme P, Formation of microemulsions for using as cosmeceutical delivery systems: effects of various components and characteristics of some formulations. Drug Deliv Transl Res., 2016; 6(3): 254-262.

66. Xu Q, Nakajina M, Liu Z, Shiina T, Soybean-based surfactants and their applications. In: Soybean Applications and Technology, Nakajima M, (Ed.), IntechOpen: Rijeka, 2011; 341-364.

67. Xuan XY, Cheng YL, Acosta E, Lecithin-linker microemulsion gelatin gels for extended drug delivery. Pharmaceutics, 2012; 4(1): 104-129.

68. Yati K, Srifiana Y, Putra F, Effect of optimization of Tween 80 and propylene glycol as a surfactant and cosurfactant on the physical properties of aspirin microemulsion. Int J Appl Pharm., 2017; 9(1): 127-129.

69. Zhang J, Froelich A, Michniak-Kohn B, Topical delivery of meloxicam using liposome and microemulsion formulation approaches. Pharmaceutics, 2020; 12(3): 282: $1-24$. 